\title{
Need for public health policies in the elderly population: indicators of aging in a Social Security Institute in Mexico
}

\author{
Daniel López-Hernández*, Nadhyieli Orozco-Campos, Irma Luz Riva Palacio Chiang y Sam and \\ Margarita Blanco-Cornejo \\ Sub-directorate of Prevention and Health Protection, Instituto de Seguridad y Servicios Sociales de los Trabajadores del Estado, Ciudad de México, \\ Mexico
}

\begin{abstract}
Introduction: An integral diagnosis of population contemplates within its components the population demographic analysis that is indispensable in the formulation of public policies. Population policy has a clearly transversal nature, since all actions in the economic, social, political, cultural, geographical, and obviously, demographic fields, have direct or indirect repercussions on it. Objectives: To determine the population dynamics and the global growth of the older adult population (OAP) of 60 years and more. Materials and methods: Cross-sectional, retrospective study. The information was obtained from the statistical yearbooks of the institute of security and social services of state workers, Mexico (1999-2015). Several demographic ageing indicators were analyzed. Results: There was a constant increase in percentage points in the proportion of OAP, index of ageing, demographic dependency ratio of old age, global index of dependence, index of dependence of old people, and index of the active population structure $(6,19.2,15.5,8.5,8.2$ and $31.2 \%$, respectively). The indicator global index of dependence and masculinity showed a decrease $(0.6$ and $3.1 \%$, respectively). Conclusions: Our data provide evidence that suggests modifying and generating public policies according to OAP.
\end{abstract}

KEY WORDS: Population dynamics. Public health policies. Elderly population. Indicators of ageing.

\section{Introduction}

Globally, an epidemiological transition of the elderly population $(E P)^{1,2}$ is observed, which constitutes a challenge for society and health systems in terms of medical care, and in particular for the allocation of the health services' budget, which should properly respond to population aging. In addition, this phenomenon generates challenges to the design and development of new public policies, based on factors associated with the population of each country ${ }^{2-4}$. However, although the World Health Organization proposes general strategies for action to achieve an active aging, public policy plans should be based on the sociodemographic characteristics of each population. Therefore, it is important to know the population dynamics, which is a fundamental demographic measure for key policies to be adopted, based on real data, and thus generate systemic changes and achieve active and healthy aging, which will result in a comprehensive public health response. In this context, Article 34, section XII of the Law of the Institute of Security and Social Services of State Workers (ISSSTE - Instituto de Seguridad y Servicios Sociales de los Trabajadores del Estado) contemplates that, as part of preventive health care services aimed at protecting the health of the beneficiaries, the Institute will include aging care. However, the ISSSTE General Organization Manual, within its organizational structure, does not include any Head Office of Services or Department for healthy aging, which limits interventions to curative and rehabilitation medical care at the gerontology modules established within primary care
Correspondence:

*Daniel López Hernández

E-mail: daniel16042016@gmail.com
Date of reception: 06-03-2019

Date of acceptance: 19-03-2019

DOI: 10.24875/GMM.M19000281
Gac Med Mex. 2019;155 (Suppl 1):S1-S5

Contents available at PubMed www.gacetamedicademexico.com 
Tabla 1. Historical profile of aging demographic indicators at the Institute of Social Security and Services of State Workers for the 1999-2015 period

\begin{tabular}{|c|c|c|c|c|c|c|c|}
\hline Indices & 1999 & 2000 & 2001 & 2002 & 2003 & 2004 & 2005 \\
\hline 60-year-old and older EP & $8,575,395$ & $8,722,188$ & $8,870,250$ & $8,933,708$ & $8,971,039$ & $9,066,869$ & $9,193,650$ \\
\hline$<60$-year-old population & $1,321,300$ & $1,343,673$ & $1,366,273$ & $1,375,781$ & $1,381,279$ & $1,395,834$ & $1,414,559$ \\
\hline Proportion of 60-year-old and older EP (\%) & 13.35 & 13.35 & 13.35 & 13.34 & 13.34 & 13.34 & 13.33 \\
\hline Old-age index (\%) & 37.52 & 37.55 & 37.6 & 37.66 & 37.74 & 37.81 & 37.88 \\
\hline Old-age dependency ratio (\%) & 26.14 & 26.12 & 26.09 & 26.05 & 26.01 & 25.97 & 25.91 \\
\hline Generacional de la ancianidad (\%) & 2.74 & 2.74 & 2.75 & 2.76 & 2.76 & 2.77 & 2.78 \\
\hline Global dependency (\%) & 83.94 & 83.82 & 83.65 & 83.4 & 83.12 & 82.87 & 82.6 \\
\hline EP dependency (\%) & 18.49 & 18.47 & 18.45 & 18.42 & 18.38 & 18.35 & 18.31 \\
\hline Active population structure (\%) & 60.81 & 60.85 & 60.91 & 61 & 61.11 & 61.2 & 61.29 \\
\hline
\end{tabular}

units. The purpose of this study is to determine the profile of the dynamics and growth of the ISSSTE-covered population aged 60 years and older, and based on this, to analyze the implications this entails for public health policies.

\section{Methods}

A cross-sectional, retrospective study was conducted in accordance with the good clinical practice of our legislation and with the Declaration of Helsinki, which included the population covered by the ISSSTE. The information was obtained from statistical yearbooks for a period of 17 years (1999-2015), which do not include patient data. The EP was defined as people aged 60 years and older. The following demographic aging indicators were calculated: the EP proportion $(P)$, EP growth rate and several aging indices (old-age demographic dependency, male gender, old-age generational, global dependency, elderly population dependency, and active population structure ratios, the Friz index [Friz-I], Sundbarg index [Sundbarg-I], Burgdöfer index [Burgdöfer-I] and Sauvy index [Sauvy-I]), based on formulas and criteria reported by the Ministry of Health and Torres-Degrós,6. According to Friz-I, Sundbarg-I and Burgdöfer-I, the population was classified into three categories: young, mature and elderly population ${ }^{6}$. All quantitative variables are described as arithmetic mean, standard deviation (SD), minimum (min), maximum (max), median $(m d)$, range $(r)$ and interquartile range (IQR). For the population pyramid, the percentage of people by five-year groups and gender was calculated. The proportions were compared using the chi-square test. The indicators of aging by sex were compared with the comparison of medians test for independent samples. P-values $<0.05$ (2-tailed tests) were considered significant. Data were analyzed with the SPSS ${ }^{\circledR}$ statistical package for Windows $^{\circledR}$, version 21.

\section{Results}

The covered population went from 9,896,695 (1999) to $12,973,731$ people (2015) (an increase of $3,077,036$ individuals). Of the total number of beneficiaries, $19.4 \%$ (males: $9.3 \%$, females: $10.1 \%$ ) (Fig. 1) corresponds to EP (growth of 1,190,365 individuals, corresponding to $6 \%)$. In turn, out of this age group $(n=2,511,665), 48 \%(n=1,207,300)$ are males and $52 \%(n=1,304,365)$ are females. A significant increase and decrease were observed in the EP-P (1999: $13.4 \%$ vs. $2015: 19.4 \% ; p<0.0001$ ) and in the population groups between 0-14 (1999: $35.6 \%$ vs. 2015: $34.2 \% ; p<0.0001$ ) and $15-59$ years (1999: $51.1 \%$ vs. $2015: 46.5 \% ; p<0.0001)$, respectively. The change of the population pyramid shows a broadening in the age groups corresponding to the tip and a highly noticeable narrowness in the center and barely noticeable at its base (Fig. 1). The EP growth rate significantly increased, from 1 to 9 people per 100 beneficiaries (2000-2005: 1, 2005-2010: 2.4 and 2010-2015: 9.1). Population average percentage growth in 17 years is $1.68 \%$ (SD: 0.74 ; min: 0.41 ; max: 3.37; r: 2.95; md: 1.66; IQR: 1.34-1.81). In absolute terms, an average growth of 192,315 beneficiaries is observed (SD: 89,782; min: 42,829; max: 403,871; r: 361,042; md: 177,104; IQR: 163,251-220,752). Average values for the aging indicators are: EP-P 14.33 


\begin{tabular}{|c|c|c|c|c|c|c|c|c|c|}
\hline 2006 & 2007 & 2008 & 2009 & 2010 & 2011 & 2012 & 2013 & 2014 & 2015 \\
\hline $9,359,023$ & $9,518,045$ & $9,795,683$ & $10,046,672$ & $10,397,451$ & $10,583,333$ & $10,794,878$ & $10,276,780$ & $10,372,518$ & $10,462,066$ \\
\hline $1,439,925$ & $1,462,886$ & $1,505,061$ & $1,542,811$ & $1,595,903$ & $1,623,397$ & $1,654,731$ & $2,353,789$ & $2,431,299$ & $2,511,665$ \\
\hline 13.33 & 13.32 & 13.32 & 13.31 & 13.31 & 13.3 & 13.29 & 18.64 & 18.99 & 19.36 \\
\hline 37.9 & 38.09 & 38.16 & 38.24 & 38.33 & 38.35 & 38.36 & 54.11 & 55.32 & 56.66 \\
\hline 25.9 & 25.77 & 25.72 & 25.66 & 25.6 & 25.56 & 25.53 & 39.71 & 40.67 & 41.66 \\
\hline 2.78 & 2.81 & 2.82 & 2.83 & 2.84 & 2.85 & 2.85 & 2.23 & 2.19 & 2.14 \\
\hline 82.53 & 81.79 & 81.52 & 81.21 & 80.87 & 80.82 & 80.6 & 91.47 & 91.99 & 92.41 \\
\hline 18.3 & 18.2 & 18.17 & 18.12 & 18.08 & 18.05 & 18.03 & 25.53 & 26.09 & 26.67 \\
\hline 61.32 & 61.58 & 61.67 & 61.78 & 61.9 & 61.94 & 61.96 & 91.71 & 91.89 & 92.03 \\
\hline
\end{tabular}
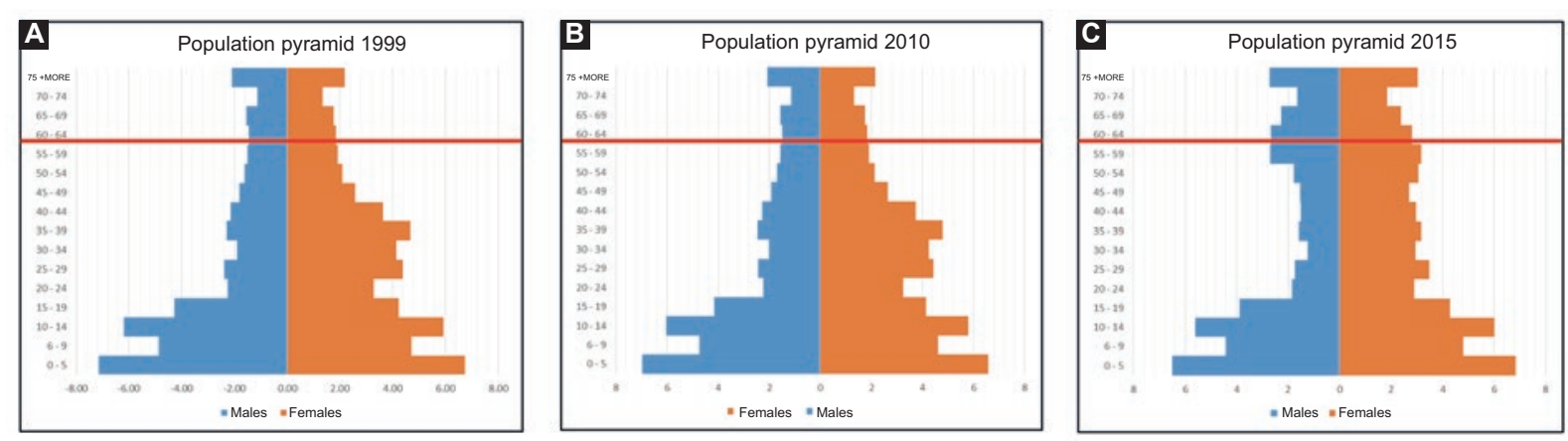

Figure 1. A: 1999 population; B: 2010 population; C: 2015 population; Institute of Social Security and Services of State Workers population pyramid.

(md: 13.3; IQR: 13.35-13.32); aging index 41.0 (md: 38.1; IQR: 38.4-37.7); old age demographic dependency ratio index 28.5 (md: 25.97; IQR: 26.13-25.69); global dependency index 84.0 (md: 82.87; IQR: 83.88-81.37); elderly population dependency index 19.7 (md: 18.35; RIC: 18.48-18.14), active population structure index 66.8 (md: 61.58; IQR: 61.95-61.06), old age generational index 2.7 (md: 2.77 ; IQR: 2.822.74) and male gender index 80.2 (md: 80.66 ; IQR: 80.95-80.45). When comparing 1999 and 2015 data, a significant increase was observed in all indicators (EP-P: 6\%; aging index: 19.2\%; old age demographic dependency ratio index: 15.5\%; global dependency index: $8.5 \%$; elderly population dependence index: $8.2 \%$ and active population structure index: $31.2 \%)$; with the exception of old age generational index and male gender index, which showed a significant decrease ( 0.6 and $3.1 \%$, respectively). When each indicator was analyzed, the two indicators that show a constant increase are the aging index and the active population structure index. The indicator that showed a gradual increase and a subsequent decrease, as of 2013, was the old age generational index. Furthermore, the EP-P, and the old age demographic dependence, global dependence and elderly population dependence ratio indices showed a gradual decrease in the 1999-2012 period, and from 2013 on, a steady increase in all of them (Table 1). According to the values obtained by Friz-I, our population corresponds to a young population, which is consistent with the Sundbarg-I, but the Burgdöfer-I results indicate a population change, from a young to a mature population, while the Sauvy-I suggests an elderly population (indices higher than $30 \%$ ). The analysis by gender shows the same patterns, with the exception of the of the active population structure index, where the male population showed an increase in 2013. In addition, the EP-P, the old age demographic dependence, global dependence, elderly population dependence and active population structure ratio indices are significantly higher in males than in females, while the values of the aging and old age generational indices are significantly higher in females (Table 2). 
Tabla 2. Comparison of old-age indicators by gender

\begin{tabular}{|c|c|c|c|c|}
\hline Indicator & $\begin{array}{l}\text { Total population } \\
\qquad \begin{array}{c}\mathrm{N}=17 \\
\text { Md (IR) }\end{array}\end{array}$ & $\begin{array}{l}\text { Males } \\
\mathrm{N}=17 \\
\mathrm{Md}(\mathrm{IR}\end{array}$ & $\begin{array}{l}\text { Females } \\
\qquad \begin{array}{l}N=17 \\
\text { Md (IR) }\end{array}\end{array}$ & p-value \\
\hline EPP & $13,34(13,35-13,32)$ & $13,97(13,97-13,96)$ & $12,83(12,86-12,78)$ & 0,001 \\
\hline Al & $38,09(38,36-37,70)$ & $34,91(35,25-34,41)$ & $41,41(41,61-41,15)$ & 0,001 \\
\hline OADDR & $25,97(26,13-25,69)$ & $30,26(30,66-30,89)$ & $22,66(23,03-22,89)$ & 0,001 \\
\hline OAGI & $2,77(2,82-2,74)$ & $2,31(2,37-2,27)$ & $3,19(3,24-3,16)$ & $<0,001$ \\
\hline GDI & $82,87(83,88-81,37)$ & $104,59(106,22-102,11)$ & $68,44(69,13-67,45)$ & $<0,001$ \\
\hline EPDI & $18,35(18,48-18,14)$ & $21,84(22,03-21,54)$ & $16,03(16,13-15,87)$ & 0,001 \\
\hline APSI & $61,58(61,95-61,06)$ & $66,48(67,18-65,52)$ & $58,45(58,61-58,23)$ & 0,001 \\
\hline
\end{tabular}

\section{Discussion}

It has been estimated that, in 2025 , the projected EP-P for the region of the Americas will be similar to the projection for Mexico for 20307. However, this proportion is currently lower than our study population, which represents an important demographic change and an inescapable reality. Regarding the growth rate of our population, a significant increase was observed, which is higher than expected at the national level ${ }^{5}$. These data represent an important challenge for the institution and its social patrimony, since an increasing number of people require specialized healthcare, access to the pension system and social protection, inclusion in health promotion and disease prevention strategies, participation in empowerment programs, mutual aid groups and recreational activities that favor active and healthy aging ${ }^{8}$; hence, inclusive policies for this population group. Our data indicate that the potential needs for population-targeted social support will be greater than for other institutions in the country ${ }^{9}$, that social assistance support for the beneficiary population will be a highly important factor to be considered in the development of public policies and even that these policies will have to consider gender-related differences (Table 2). These differences are a reflection of the larger number of women of working age $(2,306,634$ [38\%] vs. 3,722,258 [62\%], men and women aged 15 to 59 , respectively) and a more homogeneous proportion of $\operatorname{EP}(1,207,300$ [48\%] vs. 1,304,365 [52\%] men and women, respectively). Another very important aspect to consider is the caregivers of the 65-year-old and older EP. Currently, there are programs that contemplate social assistance, such as domiciliary visits; however, the population in charge of caring for this age group is a population vulnerable to burnout, due to the inherent activities and the change in lifestyle it represents. The old-age generational index has been slowly increasing since 1999, unlike Puerto Rico, where it has decreased ${ }^{6}$. Consequently, our data provide evidence that suggests the need for the generation of programs aimed at preventing caregiver burnout. The global dependency index (total population: 92/100, men: $113 / 100$ and women: 78/100 economically active people) and the old-age dependency ratio (total population: 26/100, men: 32/100 and women: 22/100 people of working age), indicate that there are more men dependent on economically active and working-age people in comparison with women, which suggests that the male population may be more likely to require social assistance support and care by direct relatives such as wives, children and siblings; but in our setting, the highest percentage of primary caregivers (unpublished data) and the highest proportion of people of working age are women and, therefore, a higher prevalence of caregiver burnout would be expected in this population group. This implies incorporating empowerment actions into educational programs aimed at the population as a priority public health policy in preventive medicine. Given that the population aged 15 to 64 years is considered the structure of the active population that is fit to work $^{6}$, it is important for the degree of aging of this sector to be known, not only for its economic, social and cultural implications, but also for its importance in the generation of public health policies, since this population group demands different dynamics for health systems. Our findings indicate that, although we can consider that the structure of the working population is young, there is already a transition to an old working population, which will increase the demand for the 
Institute's pension and social protection system and the demand for care of the EP, which will be higher in the years to come. In addition, we can infer that this will increase the prevalence of diseases that are characteristic of this population group and, consequently, expenditure for the health system. Therefore, our findings provide evidence to consider the inclusion of programs of financial investment in health services aimed at this population as a feasible public policy. In this regard, savings to health systems have been shown to be a viable policy for each dollar invested in health promotion programs ${ }^{9}$. Although our data only include ISSSTE information, they are representative of the national beneficiary population. In addition, the analyzed period is a broad period, which allowed observing the population dynamics of each indicator and broaden the perspectives for the application of our findings. Our data show that health policy should contemplate as priority and immediate measures: improving access to preventive medicine, adapting health services to the EP, contemplating gender differences, being inclusive of the EP and the working age population; considering population dynamics, guaranteeing the supply of essential medications, providing an adequate infrastructure to primary care services, including higher incorporation of material, financial and human resources in the field of geriatrics, incorporating programs that are ad hoc to the population and including a comprehensive intervention model for active and healthy aging. Addressing this type of measures as a public health policy priority is essential for generating comprehensive care for the population and improving health expenditures, in order to respond to the future population challenge. In this context, it is necessary to build a legal framework with social security and protection mechanisms that serve to clearly and expeditiously fight poverty, vulnerability and social exclusion, and that ensure the generation of national social protection floors that are inclusive and non-discriminatory for this population group, as well as defining and delimiting the necessary criteria to assess the suitability of ensuring a decent life and incorporate the participation of people working in the informal economy, disadvantaged groups and people with special needs; defining and providing basic social security guarantees to the population residing in the country, under the principles of universality of protection, based on social solidarity, the right to benefits prescribed by a legislative framework; that includes respect for the rights and dignity of people, solidarity in financing, associated with the search for an optimal balance between the responsibilities and interests of those who finance and benefit from social security programs; with inclusion of financing mechanisms and benefit systems; sound, responsible and transparent financial management and administration; financial, fiscal and economic sustainability, duly taking social justice and equity into account; consistency with social, economic, health and labor policies; coherence between the institutions responsible for the provision of social protection services; high-quality public services that improve the performance of social security systems; efficacy of and accessibility to complaint and appeal procedures; regular monitoring of application and periodic evaluation; full respect for collective bargaining and freedom of association for all workers, and tripartite participation with organizations representing employers and workers, as well as consultation with other relevant organizations and representatives of interested persons ${ }^{10}$.

\section{Conclusion}

Our data provide evidence that suggests the incorporation of social security and protection strategies and mechanisms according to population dynamics based on the use of demographic indicators of aging and EP growth, with the purpose to strengthen primary health care in the public system for this population group.

\section{Conflict of interests}

The authors declare that they have no conflicts of interest.

\section{References}

1. Temas de Salud. Envejecimiento [Internet]. Ginebra: Organización Mundial de la Salud [10 ago 2017]. Disponible en: https://www.who.int/topics/ ageing/es/.

2. Organización Mundial de la Salud. Informe mundial sobre el envejecimiento y la salud. EE.UU.; 2015

3. Bloom DE. 7 billion and counting. Science. 2011;333:562-9

4. Christensen K, Doblhammer G, Rau R, Vaupel JW. Ageing populations: the challenges ahead. Lancet. 2009:374:1196-208.

5. Perfil epidemiológico del adulto mayor en México 2010. México: Secretaría de Salud, Subsecretaría de Prevención y Promoción de la Salud, Dirección General de Epidemiología; 2011.

6. Torres-Degró A. Envejecimiento demográfico: un acercamiento a los métodos cuantitativos. CIDE digital [Internet]. 13 ago 2017 [citado 11 ago 2017];1(2):79-02. Disponible en: https://revistas.upr.edu/index.php/ cidedigital/article/view/11864.

7. Crecimiento acelerado de la población adulta de 60 años y más de edad: Reto para la salud pública [Internet]. Organización Panamericana de la Salud; 2012. Disponible en: https://www.paho.org/hq/index.php?option=com_content\&view=article\&id=2796:2010-crecimiento-acelerado-poblacion-adulta-60-anos-mas-edad-reto-salud-publica\&ltemid=1914\&lang=es.

8. Secretaría de Desarrollo Social. Subsecretaría de Prospectiva, Planeación y Evaluación I. Avances y retos de la política social. Índice de envejecimiento a nivel global y en México. Indicadores de Desarrollo Social. 2013;2(63).

9. Banke-Thomas AO, Madaj B, Charles A, van den Broek N. Social Return on Investment (SROI) methodology to account for value for money of public health interventions: a systematic review. BMC Public Health. 2015;15:582.

10. Recomendación sobre los pisos de protección social, 2012 (núm. 202). Ginebra: Organización Internacional del Trabajo, 101ª reunión CIT (14 junio 2012); 2012. 